\title{
The Impact of Government Policies on Small and Medium-sized Cross-border E-commerce Companies in Xiamen in the Post-epidemic Era
}

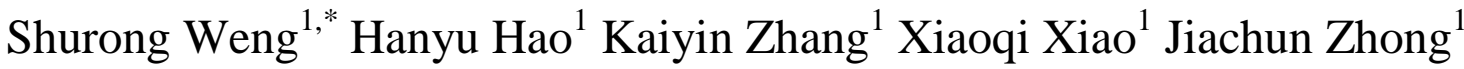 \\ ${ }^{1}$ School of Business Management, Xiamen HuaXia University, Xiamen, Fujian361021, China \\ "Corresponding author. Email: wsr@hxxy.edu.cn
}

\begin{abstract}
This article mainly studies the positive role of government policies on small and medium-sized cross-border ecommerce companies when facing emergency epidemic and the importance of improving cross-border ecommerce policies in the future. It conducted by questionnaire surveys through the research on the impact of small and medium-sized cross-border e-commerce companies in Xiamen before and after the epidemic and the effect under the help of government policies.
\end{abstract}

Keywords: Epidemic, Xiamen small and medium-sized cross-border e-commerce enterprises, Government policies.

\section{INTRODUCTION}

\subsection{Situation Before Epidemic}

In 2018, the export value of Xiamen's foreign trade enterprises was RMB333.85 billion yuan, and the import value was RMB266.35 billion yuan, of which the export value of cross-border e-commerce enterprises was RMB20.87 billion yuan, and the import value was RMB264 million yuan; retail value of imports and exports was 55.255 million pieces, there was a year-on-year increase of $14.5 \%$. Among them, Amazon ranked first in the turnover of cross-border e-commerce platforms in Xiamen, and eBay had a compound annual growth rate of $300 \%-400 \%$ in Xiamen, in the lead of other platforms.

From January to August 2019, Xiamen Customs supervised a total of 1.2077 million pieces of crossborder e-commerce retail export commodities, at an increase of $175.27 \%$. Among them, 506,400 pieces were exported in August, with a year-on-year increase of 4 times, which was doubled for three consecutive months. Xiamen had gradually become an important export port for cross-border ecommerce commodity.

\subsection{Situation After Epidemic}

In the first quarter of 2020 in Xiamen, according to the data, Xiamen's cross-border ecommerce business was raised against the trend, with a total of 9.331 million pieces of customs clearances, at a year-on-year increase of $105.2 \%$. Among them, the cross-border e-commerce imports and exports quantity was total $1,670,700$ pieces with a value of RMB276 million yuan under 9610 model, at a year-on-year increase of 9.4 times. After the first quarter, to July 2020, Xiamen enterprises' cross-border e-commerce imports and exports (including B2B and B2C) value was approximate RMB1.677 billion yuan, at an increase of more than 70 times. Among them, cross-border e-commerce retail imports and exports value was about 1.664 billion yuan, at an increase of 74 times.

In other words, during the epidemic period, Xiamen's cross-border e-commerce business not only suffered heavy losses as expected, but also flew in the opposite direction, which was curious. This article started with the policies issued by the Xiamen Municipal Government during the epidemic, and tried to explore the impact of government policy support on cross-border ecommerce companies. 


\section{THE MAIN PROBLEMS FACED BY XIAMEN SMALL AND MEDIUM-SIZED CROSS-BORDER ENTERPRISES DURING THE EPIDEMIC}

In 2019, Xiamen's cross-border e-commerce retail imports and exports quantity reached 55.255 million pieces, with a year-on-year increase of $14.5 \%$. Its export value was RMB20.87 billion yuan, accounting for $6.25 \%$ of Xiamen's total foreign trade export volume. Among them, small and medium-sized cross-border e-commerce companies accounted for about $80 \%$ of the market share, which commodities mainly be sell on thirdparty platforms, it accounting for $93 \%$ of crossborder e-commerce trade volume. In 2019, in
Xiamen's cross-border e-commerce platform turnover, Amazon ranked first, and the potential development of the eBay platform in Xiamen was also rapidly increased, with a compound annual growth rate of $300 \%-400 \%$, ahead of other platforms. This showed that small and mediumsized cross-border e-commerce companies were an important part of Xiamen's e-commerce market.

This article conducted an online questionnaire survey on nearly 100 small and medium-sized cross-border companies in Xiamen, mainly focused on the impact of the epidemic on small and medium-sized cross-border e-commerce companies, the impact of government policies on companies, and the expectations of companies on the government's follow-up policies.

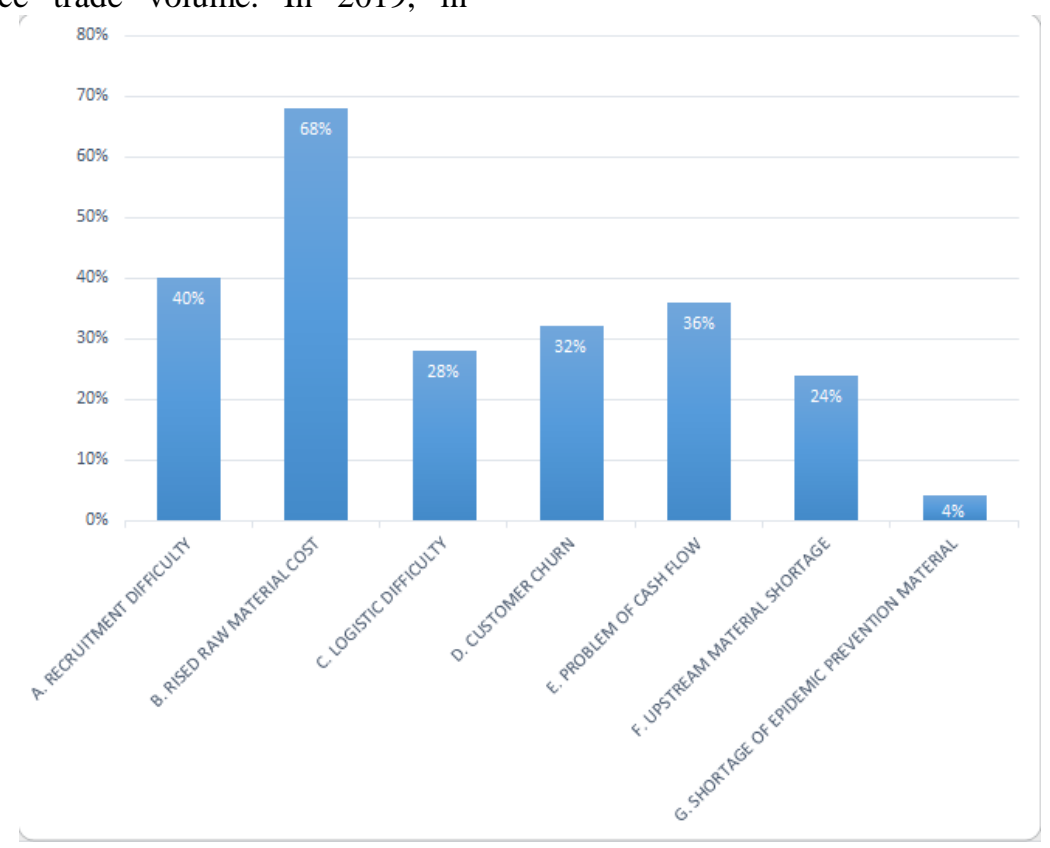

Figure 1 The problems facing during epidemic.

From "Figure 1", we could see that small and medium-sized cross-border e-commerce companies in Xiamen face four main problems during the epidemic: rising raw material costs, difficulty in recruiting workers, shortage of capital flows, and customer churn. Among them, the cost of raw materials and other costs were increased as high as $68 \%$ up, which showed that it was the most serious problem that plagued small and medium-sized cross-border companies during the epidemic. With the reduction of labor and production during the epidemic, the supply of upstream raw materials had been in short supply, and the cost had been to increase accordingly. There was no doubt that the corresponding increase in the cost of products would be accompanied with a corresponding increase in the products' price, thus losing the price advantage in international market and then led to weaken competitiveness.

The second largest proportion was the difficulty of recruiting, which was occupied $40 \%$. The epidemic had led to strict prevention and control of the flow of personnel in many places. Employees couldn't return to Xiamen on time due to the epidemic. Although they were allowed to be transferred conditionally at later stage, most employees still chose to return late for safety. These restricted the normal operation of small and medium-sized cross-border e-commerce enterprises, and led to higher unit employment cost. The lack of 
cross-border e-commerce talents had been become an important factor to hinder the development of cross-border e-commerce activities.

The followed question by general reflection was the capital flow. Due to raw material costs rising, orders were decreased or even been canceled, which caused the problem of capital flow. At the same time, the goods couldn't be shipped as schedule or the shipping cycle getting longer due to the epidemic accompanied with the high risk of customer default. It was also the reason of problems in the flow of funds. Thus, some small and medium enterprises had to be on the verge of bankruptcy.

Finally, there was the problem of customer churn. Due to the impact of the epidemic, the market was panic, and the purchasing power of both Chinese and overseas markets was declined in whole. Household clean and care products and health care products had become the first choice of customers, followed by life-essential categories, such as oil, grain, milk powder and noodles. However, the main business of Xiamen small and medium-sized cross-border e-commerce companies was non-essential products such as shoes and clothes and others which demand was inevitably decline during the epidemic. Meanwhile, the logistic difficulty and unemployment also affected the purchasing power of customers hardly, then accompanied with heavy customer churn.

\section{GOVERNMENT POLICIES ON XIAMEN ENTERPRISES DURING THE EPIDEMIC}

In view of the huge impact of the epidemic on enterprises, Xiamen had successively issued the following documents: "Notice of the Xiamen Municipal People's Government on Several Measures to Support Enterprises to Cope with the Pneumonia Epidemic Caused by the Novel Coronavirus", "Notice of the Xiamen Municipal Taxation Bureau of the State Administration of Taxation on Several Measures to Fully Support the Work to Fight the Novel Coronavirus ", "Xiamen City's Convenience Guide to Accelerate the Orderly Resumption of Construction Projects and work in Response to the Novel Coronavirus Pneumonia Epidemic". These policies provided corporate incentives in terms of taxation, social security, labor, and rent. For example, the company could apply for an extension of tax payment not exceed three months in accordance with the regulation of pending tax declaration period in February 2020, if they did have special difficulties; for those enterprises and small private business had difficulties in production and operation during epidemic period, they were allowed to register and pay social insurance premiums 6 months after the epidemic ends without forfeit penalty; providing fixed-line chartered service for those employees needed to be back to Xiamen; publishing the regulations that the rent could be free for one month and halved for two months if small and mediumsized enterprises and small private business rent government assets for business use; the state-owned enterprises were also be encouraged to implement it accordingly.

On March 20, 2020, the "Notice of Xiamen Municipal Bureau of Commerce on Increasing Support for Cross-border E-commerce Business in the First Quarter" was issued specifically to support cross-border e-commerce companies who operated by themselves or in third-party platform. It confirmed to provide a logistics subsidy of not more than RMB1 million yuan based on $2 \%$ of the transaction volume for those enterprises whose transaction volume increased more than RMB3 million yuan year-on-year in the first quarter of 2020. By the way, the "Notice on Tax Policies for Cross-border E-commerce Retail Imports" also stipulated that the tariff rate was temporarily down to $0 \%$ if the single transaction volume was within RMB 2,000, and the individual annual transaction volume was within RMB 20,000. The import valueadded tax and consumption tax was temporarily charged at $70 \%$ based on tax payable. Only when single transaction and the individual annual transaction exceeded the limit, or unit dutiable value exceeded RMB2,000 yuan, it would be levied fully tax accordance with the general trade method.

\section{THE IMPACTS OF GOVERNMENT POLICIES ON XIAMEN SMALL AND MEDIUM-SIZED CROSS- BORDER ENTERPRISES}

According to the government policy promulgated in Section III, in addition to providing fixed-point chartered services for employees who need to be back to Xiamen, the Xiamen Municipal Government also provided a subsidy of 500 yuan per person to the company for recruiting those laborers with finished employment registration and payment of social security who was first time to Xiamen and worked in Xiamen more than three months. At the same time, in response to the company's difficulty in employment, the company's 
recruitment information would be accurately transferred to enhance companies' recruitment.

In addition, the Xiamen Municipal Government had implemented a one-month rent reduction and two-month rent reduction policy for operating government assets, as well as encouraging banking institutions to increase support on small and micro enterprises who were greatly affected by the epidemic, such as not allowing to draw out loans, cut off loans, or press down on loans. Concerned the companies that had been severely affected by the epidemic, banking institutions needed to extend or renew their loans to solve their capital flow problems accordingly.

\subsection{Positive Impact}

Because of these "hard policies" issued by the government, Xiamen's market confidence was rapidly recovering. Xiamen had made most effort to stabilize foreign trade, expand its advantages in cross-border e-commerce platforms, and promote foreign trade development. Cross-border ecommerce companies had reduced logistics costs by expanding cross-border trade e-commerce, bonded cross-border trade e-commerce and other businesses that were included in customs trade statistics. Meanwhile, their supply chain management level was improved by using application information, which also improved their own comprehensive competitiveness and then more well-known cross-border e-commerce companies were attracted to Xiamen.

At the same time, with the support of policies, many cross-border e-commerce companies had begun to transform, such as creating new products and new brands to meet international market demand, and then achieving the aim of "going out"; using the methods of self-construction, acquisition, joint venture or leasing, etc., reasonably planning and layout public overseas warehouses in in the traditional market \& emerging market; expanding cross-border e-commerce import and export through the "cross-border e-commerce + overseas warehouse" model; starting information system construction and cross-border e-commerce platform application to improve supply chain service capabilities.

After the epidemic, cross-border e-commerce companies had paid more attention to set up the related talent training bases, strengthen crossborder e-commerce practical training courses, and improve the professional quality of cross-border e- commerce staff. With the support of policies, Xiamen built a key cross-border e-commerce industrial park, highlighted the characteristics of the park, improved supporting services, developed dislocation, and gradually formed a scale and agglomeration effect. To promote the joint development of cross-border e-commerce online platforms and offline parks through optimizing the business functions of the "single window" and cross-border e-commerce public service platforms, encouraging to form new business formats, expanding service functions such as information sharing, financial services, and smart logistics.

\subsection{Shortage}

Although government policies had a huge positive impact and advantages for Xiamen enterprises, including cross-border e-commerce companies, there were still many restrictions on small and medium-sized enterprises, including cross-border e-commerce companies, accompany with limited implementation efforts. As shown in "Figure 2", 55\% of enterprises still regarded tax reduction or exemption as the biggest support policy, which showed that the current reduction and exemption policies were not enough for them. Another $45 \%$ of enterprises hoped to restore logistics channels as soon as possible. Judging from the policies that had been issued so far, there were not too many or too good targeted recovery measures, especially international logistics channels. In addition, $35 \%$ of companies expected to introduce policies to reduce or exempt social security fees. This indicated that the existing measures were not strong enough by allowing companies or individuals to extend the payment of social security fees for 6 months. After all, the epidemic may exist for a long time, and it would be harmful to companies continually. The impact of full resumption of work and production would also exist for a long time. The main cultivation policy introduced by the Xiamen Municipal Government during the epidemic was covered on a small number of companies, which were with a year-onyear increase of more than RMB3 million yuan in transaction volume according to customs statistic in first quarter in 2020. Even so, most of them still indicated that there was little support getting from the government's subsidy policy. After all, only very few companies which were generally large companies that could achieve this growth rate during the epidemic. Although participating in overseas exhibitions could provide booth and personnel subsidies according to the country and 
region of the exhibition, but such subsidy was equal to zero since the exhibitions were basically canceled or postponed during the epidemic. Therefore, many small and medium-sized enterprises hoped that the government could introduce relevant support and subsidy policies on conducting management system certification, product certification, overseas trademark registration, overseas patent registration, purchasing overseas trademark use rights, and carrying out promotion activities on major Ecommerce platforms.

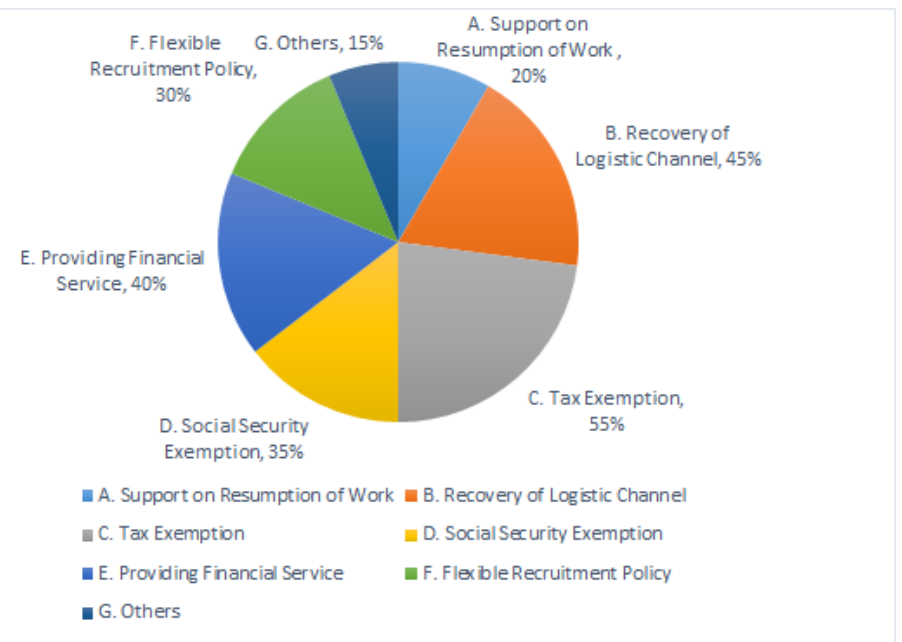

Figure 2 Expected government policies.

\section{CONCLUSION}

In general, Xiamen government actively responded to the sudden epidemic. The Xiamen Free Trade Commission also did a good job of preventing and controlling the epidemic. Simultaneously they seized the opportunities actively to construct cross-border e-commerce comprehensive experimental areas and export supervision pilots, promote the transformation and upgrading of related industries and stabilize the overall situation of foreign trade by strengthening the support to enterprise, expanding new business models, and smoothing new logistics channels and so on. Therefore, although the epidemic had caused a certain impact on cross-border e-commerce companies, the overall development of cross-border e-commerce still showed an inverse rise in 2020 under the help of the government. So if the government could introduce more or more policies focusing on small and medium-sized cross-border e-commerce companies, the development of crossborder e-commerce in Xiamen could be gone faster and better.

\section{AUTHORS' CONTRIBUTIONS}

Shurong Weng contributed to build the framework, revising \& editing, Hanyu Hao was responsible for the data collection \& analysis,
Kaiyin Zhang helped to analyse data, Xiaoqi Xiao, Jiachun Zhong wrote the manuscript.

\section{REFERENCES}

[1] Zhang JingYu, "Research on the Optimization Path of Yiwu Cross-border E-commerce Enterprise Inventory Management in the Postepidemic Period," J. Market Modernization, pp. 38-39, February 2020.

[2] Gong YongQin, ""Dangers" and "opportunities" to Chiness Cross-border Ecommerce brought by Covid-19", J. Journal of Beijing Vocational College of Labor and Social Security, Feb 2020.

[3] Li YunJia, Ding Qi, "Analysis of the Impact of Covid-19 on Cross-border E-commerce Logistics," J. Logistics Sci-Tech, pp. 67-68, July 2020.

[4] Zhang RuiYun, "The Impact \& Solution of Covid-19 on Cross-border E-commerce Sellers," J. Enterprise Observer, pp. 59-61, Aug 2020.

[5] Liu BoFei, Yang HongLing, "Opportunities and challenges of the Development of Chinese cross-border E-commerce under Covid-19," J. China Journal of Commerce, pp. 34-35, Aug 2020. 
[6] Zhan QiuSi, Zhang Chun, Feng DongFeng, Lv XiaoHui, Ma CuiPing, "The Analysis of the Impact of Covid-19 on the development of Small and Medium Sized Cross-border Ecommerce Enterprises," J. Management \& Technology of SME, pp. 136-137, Dec 2020. 